\title{
JNK and p38 inhibitors increase and decrease apoptosis, respectively, in pyrogallol-treated calf pulmonary arterial endothelial cells
}

\author{
YONG HWAN HAN, HWA JIN MOON, BO RA YOU, SUNG ZOO KIM, SUHN HEE KIM and WOO HYUN PARK \\ Department of Physiology, Medical School, Centers for Healthcare Technology Development \\ Institute for Medical Sciences, Chonbuk National University, JeonJu 561-180, Korea
}

Received June 25, 2009; Accepted August 5, 2009

DOI: 10.3892/ijmm_00000284

\begin{abstract}
Pyrogallol (PG) as a polyphenol compound induces apoptosis in several types of cells. Here, we investigated the effects of MAPK inhibitors on PG-treated calf pulmonary artery endothelial cells (CPAEC) in relation to cell death, ROS and GSH. PG inhibited the growth of CPAEC and also induced cell death, which was accompanied by the loss of mitochondrial membrane potential (MMP; $\Delta \Psi_{\mathrm{m}}$ ). PG decreased the ROS level and increased the GSH depleted cell number in CPAEC. JNK inhibitor intensified the growth inhibition by PG whereas p38 inhibitor attenuated the growth inhibition. While MEK and p38 inhibitors decreased CPAEC death by PG, JNK inhibitor increased. None of the MAPK inhibitors significantly increased ROS level in PG-treated CPAEC. JNK inhibitor increased GSH depleted cell number in PGtreated CPAEC whereas p38 inhibitor decreased the number. MAPK inhibitors differently affected cell growth, death, ROS and GSH levels in control CPACE. In conclusion, PG induced apoptosis via the loss of MMP $\left(\Delta \Psi_{\mathrm{m}}\right)$ in CPAEC, which is accompanied by GSH depletion. JNK and p38 inhibitors increased and decreased apoptosis in PG-treated CPAEC, respectively, which were correlated with GSH depletion.
\end{abstract}

Correspondence to: Dr Woo Hyun Park, Department of Physiology, Medical School, Chonbuk National University, JeonJu, Korea E-mail: parkwh71@chonbuk.ac.kr

Abbreviations: PG, pyrogallol; EC, endothelial cells; CPAEC, calf pulmonary arterial endothelial cells; ROS, reactive oxygen species; MAPK, mitogen-activated protein kinase; MEK, MAP kinase or ERK kinase; ERK, extracellular signal-regulated kinase; JNK, c-Jun N-terminal kinase; MMP $\left(\Delta \Psi_{\mathrm{m}}\right)$, mitochondrial membrane potential; FBS, fetal bovine serum; MTT, 3-(4,5dimethylthiazol-2-yl)-2,5-diphenyltetrazolium bromide; FITC, fluorescein isothiocyanate; $\mathrm{H}_{2}$ DCFDA, 2',7'-dichlorodihydrofluorescein diacetate; DHE, dihydroethidium; GSH, glutathione; CMFDA, 5-chloromethylfluorescein diacetate; PI, propidium iodide

Key words: pyrogallol, apoptosis, calf pulmonary arterial endothelial cells, mitogen-activated protein kinase inhibitor, reactive oxygen species, glutathione

\section{Introduction}

Pyrogallol (PG) is a polyphenol compound and known as a superoxide anion $\left(\mathrm{O}_{2}{ }^{-*}\right)$ generator $(1,2)$. The $\mathrm{O}_{2}{ }^{--}$belongs to the reactive oxygen species (ROS) including hydrogen peroxide $\left(\mathrm{H}_{2} \mathrm{O}_{2}\right)$ and hydroxyl radical $\left({ }^{\circ} \mathrm{OH}\right)$. ROS have recently been implicated in the regulation of many important cellular events, including transcription factor activation, gene expression, differentiation and cell proliferation (3-5). A change in the redox state of the tissue and cell implies a change in the generation or metabolism of ROS. Cells possess antioxidant systems to control the redox state, which is important for their survival. Excessive production of ROS gives rise to the activation of events leading to death in several cell types (6-9). PG also induce the $\mathrm{O}_{2}{ }^{--}$-mediated death of several types of cells such as mesangial cells (10), lymphoma cells (1), glioma cells (11) and Calu-6 lung cancer cells $(12,13)$.

The mitogen-activated protein kinases (MAPKs) are a large family of serine/threonine kinases, which are major components of signaling pathways in cell proliferation, differentiation and cell death (14). There are currently four known MAPKs: the extracellular signal regulated kinase (ERK1/2), the c-Jun N-terminal kinase/stress-activated protein kinase (JNK/SAPK), the p38 and the big mitogen-activated protein kinase 1 (BMK1) (15). Each MAP kinase pathway has relatively different upstream activators and specific substrates (16). Substantial evidence demonstrates that JNK and p38 are strongly activated by ROS or by a mild oxidative shift of the intracellular thiol/disulfide redox state, leading to apoptosis $(17,18)$. ROS are also known to induce ERK phosphorylation and activate the ERK pathway (19). In most instances, ERK activation has a pro-survival function rather than pro-apoptotic effects (20).

Vascular endothelium is involved in various regulatory functions such as blood pressure, inflammation and angiogenesis (21). Fundamental to the transition of tumors from a latent to malignant state, angiogenesis involving formation of new blood vessels from pre-existing vasculature is a crucial part. The proliferation of endothelial cells (ECs; sprouting) is the early step of angiogenesis. Despite critical roles for vascular ECs in tumor biogenesis and progression, the effects of polyphenol compounds, especially PG on ECs remain relatively poorly understood. 
Here, we demonstrate that PG inhibited the growth of calf pulmonary artery endothelial cells (CPAEC) and investigated the effects of MAPK inhibitors on PG-treated CPAEC in relation to cell death, ROS and GSH.

\section{Materials and methods}

Cell culture. CPAEC were obtained from KCLB (Korean Cell Line Bank) and were maintained in humidified incubator containing $5 \% \mathrm{CO}_{2}$ at $37^{\circ} \mathrm{C}$. CPAEC were cultured in RPMI1640 supplemented with $10 \%$ fetal bovine serum (FBS) and $1 \%$ penicillin-streptomycin (Gibco BRL, Grand Island, NY). CPAEC were routinely grown in $100-\mathrm{mm}$ plastic tissue culture dishes (Nunc, Roskilde, Denmark) and harvested with a solution of trypsin-EDTA (Gibco BRL) while in a logarithmic phase of growth. CPAEC were maintained in these culture conditions for all experiments.

Reagents. PG was purchased from the Sigma-Aldrich Chemical Company (St. Louis, MO). PG was dissolved in $\mathrm{H}_{2} \mathrm{O}$ at $100 \mathrm{mM}$ as a stock solution. JNK inhibitor (SP600125), MEK inhibitor (PD98059) and p38 inhibitor (SB203580) were purchased from Calbiochem (San Diego, CA). All the reagents were dissolved in DMSO at $10 \mathrm{mM}$ as a stock solution. Cells were pretreated with each MAPK inhibitor for 30 min prior to treatment with PG. DMSO $(0.2 \%)$ was used as a control vehicle. All stock solutions were wrapped in foil and kept at $-20^{\circ} \mathrm{C}$.

Cell growth assay. The effect of drugs on CPAEC growth was determined by measuring 3-(4,5-dimethylthiazol-2-yl)2,5-diphenyltetrazolium bromide (MTT) dye absorbance of living cells as previously described (22). In brief, $3 \times 10^{4}$ cells per well were seeded in 96-well microtiter plates (Nunc). After exposure to $50 \mu \mathrm{M}$ PG with or without $10 \mu \mathrm{M}$ JNK inhibitor, MEK inhibitor or p38 inhibitor for $24 \mathrm{~h}, 20 \mu \mathrm{l}$ of MTT (Sigma) solution ( $2 \mathrm{mg} / \mathrm{ml}$ in PBS) were added to each well of 96 -well plates. The plates were incubated for further $4 \mathrm{~h}$ at $37^{\circ} \mathrm{C}$. MTT solution in the medium was aspirated off and $200 \mu 1$ of DMSO were added to each well to solubilize the formazan crystals formed in viable cells. Optical density was measured at $570 \mathrm{~nm}$ using a microplate reader (Spectra MAX 340, Molecular Devices Co, Sunnyvale, CA).

Sub-G1 cell analysis. Sub-G1 cells were determined by propidium iodide (PI, Sigma-Aldrich; Ex/Em=488/617 nm) staining as previously described (23). In brief, $1 \times 10^{6}$ cells in $60 \mathrm{~mm}$ culture dish (Nunc) were incubated with $50 \mu \mathrm{M}$ PG with or without $10 \mu \mathrm{M}$ MEK inhibitor, JNK inhibitor or p38 inhibitor for $24 \mathrm{~h}$. Cells were then washed with PBS and fixed in $70 \%$ ethanol. Cells were washed again with PBS, then incubated with PI $(10 \mu \mathrm{g} / \mathrm{ml})$ with simultaneous RNase treatment at $37^{\circ} \mathrm{C}$ for $30 \mathrm{~min}$. Cell DNA content was measured using a FACStar flow cytometer (Becton-Dickinson, San Jose, CA) and analyzed using Lysis II and CellFIT software (Becton-Dickinson) or ModFit software (Verity Software House, Inc. ME).

Annexin $V$ staining. Apoptosis was determined by staining cells with annexin V-fluorescein isothiocyanate (FITC) $(\mathrm{Ex} / \mathrm{Em}=488 / 519 \mathrm{~nm})$ as previously described (13). In brief,
$1 \times 10^{6}$ cells in $60 \mathrm{~mm}$ culture dish (Nunc) were incubated with $50 \mu \mathrm{M}$ PG with or without $10 \mu \mathrm{M}$ JNK inhibitor, MEK inhibitor or p38 inhibitor for $24 \mathrm{~h}$. Cells were washed twice with cold PBS and then resuspended in $500 \mu \mathrm{l}$ of binding buffer (10 mM HEPES/NaOH pH 7.4, $140 \mathrm{mM} \mathrm{NaCl}, 2.5 \mathrm{mM}$ $\mathrm{CaCl}_{2}$ ) at a concentration of $1 \times 10^{6}$ cells $/ \mathrm{ml}$. Five microliters of annexin V-FITC (PharMingen, San Diego, CA) was then added to these cells, which were analyzed with a FACStar flow cytometer (Becton-Dickinson).

Measurement of MMP $\left(\Delta \Psi_{m}\right)$. MMP $\left(\Delta \Psi_{\mathrm{m}}\right)$ levels were measured by the Rhodamine 123 fluorescent dye (Ex/ $\mathrm{Em}=485 / 535 \mathrm{~nm}$ ) as previously described (24). In brief, $1 \times 10^{6}$ cells in $60 \mathrm{~mm}$ culture dish (Nunc) were incubated with $50 \mu \mathrm{M}$ PG with or without $10 \mu \mathrm{M}$ JNK inhibitor, MEK inhibitor or p38 inhibitor for $24 \mathrm{~h}$. Cells were washed twice with PBS and incubated with Rhodamine $123(0.1 \mu \mathrm{g} / \mathrm{ml}$; Sigma) at $37^{\circ} \mathrm{C}$ for $30 \mathrm{~min}$. Rhodamine 123 staining intensity was determined by flow cytometry. Rhodamine 123 negative cells indicate the loss of MMP $\left(\Delta \Psi_{\mathrm{m}}\right)$ in CPAEC. MMP $\left(\Delta \Psi_{\mathrm{m}}\right)$ levels in cells except MMP $\left(\Delta \Psi_{\mathrm{m}}\right)$ loss cells were expressed as mean fluorescence intensity (MFI), which was calculated by CellQuest software.

Detection of intracellular $\mathrm{ROS}$ and $\mathrm{O}_{2}^{--}$levels. Intracellular ROS such as $\mathrm{H}_{2} \mathrm{O}_{2},{ }^{\circ} \mathrm{OH}$ and $\mathrm{ONOO}{ }^{\bullet}$ were detected by means of an oxidation-sensitive fluorescent probe dye, 2',7'-Dichlorodihydrofluorescein diacetate $\left(\mathrm{H}_{2} \mathrm{DCFDA} ; \mathrm{Ex} / \mathrm{Em}=495 / 529 \mathrm{~nm}\right)$ (25) (Invitrogen Molecular Probes, Eugene, OR). $\mathrm{H}_{2}$ DCFDA is poorly selective for $\mathrm{O}_{2}{ }^{-}$. In contrast, dihydroethidium (DHE) $(\mathrm{Ex} / \mathrm{Em}=518 / 605 \mathrm{~nm})$ (Invitrogen Molecular Probes) is highly selective for $\mathrm{O}_{2}{ }^{-}$among ROS. In brief, $1 \times 10^{6}$ cells in $60 \mathrm{~mm}$ culture dish (Nunc) were incubated with $50 \mu \mathrm{M}$ PG with or without $10 \mu \mathrm{M}$ JNK inhibitor, MEK inhibitor or p38 inhibitor for $24 \mathrm{~h}$. Cells were then washed in PBS and incubated with $20 \mu \mathrm{M} \mathrm{H}_{2} \mathrm{DCFDA}$ or DHE at $37^{\circ} \mathrm{C}$ for $30 \mathrm{~min}$ according to the instructions of the manufacturer. DCF and DHE fluorescences were detected using a FACStar flow cytometer (Becton-Dickinson). ROS and $\mathrm{O}_{2}{ }^{-}$levels were expressed as mean fluorescence intensity (MFI), which was calculated by CellQuest software.

Detection of the intracellular glutathione (GSH). Cellular GSH levels were analyzed using 5-chloromethylfluorescein diacetate (CMFDA, Molecular Probes) $(E x / E m=522 / 595 \mathrm{~nm})$ as previously described (25). In brief, $1 \times 10^{6}$ cells in $60 \mathrm{~mm}$ culture dish (Nunc) were incubated with $50 \mu \mathrm{M}$ PG with or without $10 \mu \mathrm{M}$ JNK inhibitor, MEK inhibitor or p38 inhibitor for $24 \mathrm{~h}$. Cells were then washed with PBS and incubated with $5 \mu \mathrm{M}$ CMFDA at $37^{\circ} \mathrm{C}$ for $30 \mathrm{~min}$. CMF fluorescence intensity was determined using a FACStar flow cytometer (Becton-Dickinson). Negative CMF staining (GSH depleted) cells were expressed as the percent of (-) CMF cells. CMF levels in cells except GSH depleted cells were expressed as mean fluorescence intensity (MFI), which was calculated by CellQuest software.

Statistical analysis. The results shown in Figures represent the mean of at least three independent experiments; bar, SD. 
The data were analyzed using Instat software (GraphPad Prism4, San Diego, CA). The Student's t-test or one-way analysis of variance (ANOVA) with post hoc analysis using Tukey's multiple comparison test was used for parametric data. The statistical significance was defined as $p<0.05$.

\section{Results}

Effects of MAPK inhibitors on cell growth and death in $P G$ treated CPAEC. We examined the effect of MAPK inhibitors on the growth of PG-treated CPAEC using an MTT assay. Treatment with $50 \mu \mathrm{M}$ PG inhibited the growth of CPAEC about $50 \%$ at $24 \mathrm{~h}$ (Fig. 1A). Treatment with MEK inhibitor did not affect the growth of PG-treated CPAEC (Fig. 1A). JNK inhibitor intensified the growth inhibition by PG whereas p38 inhibitor significantly attenuated the growth inhibition (Fig. 1A). All the inhibitors reduced control CPAEC growth (Fig. 1A).

Treatment with $50 \mu \mathrm{M}$ PG increased sub-G1 cell numbers in CPAEC about $28 \%$ compared with control CPAEC not treated with PG. MEK inhibitor slightly reduced the number in PG-treated CPAEC (Fig. 1B). While JNK inhibitor increased sub-G1 cell numbers in PG-treated CPAEC, p38 inhibitor decreased the number (Fig. 1B). In addition, PG increased the number of annexin $\mathrm{V}$ staining cells in CPAEC, indirectly implying that CPAEC death by PG occurred via apoptosis (Fig. 1C). MEK and JNK inhibitor each slightly decreased and increased the number, respectively (Fig. 1C). Treatment with p38 inhibitor significantly reduced the number in PG-treated CPAEC (Fig. 1C). JNK inhibitor increased annexin V-FITC positive cells in control CPAEC (Fig. 1C).

Effects of MAPK inhibitors on MMP $\left(\triangle \Psi_{m}\right)$ in PG-treated $C P A E C$. Apoptosis is closely related to the collapse of MMP $\left(\Delta \Psi_{\mathrm{m}}\right)$ (26). Thus, we determined the loss of MMP $\left(\Delta \Psi_{\mathrm{m}}\right)$ in PG-treated CPAEC using a Rhodamine 123 dye at $24 \mathrm{~h}$. As expected, the loss of MMP $\left(\Delta \Psi_{\mathrm{m}}\right)$ was observed in PG-treated cells (Fig. 2A). Similar to the results of sub-G1 and annexin V-FITC cells, MEK and JNK inhibitor each slightly decreased and increased the loss of MMP ( $\left.\Delta \Psi_{\mathrm{m}}\right)$, respectively (Fig. 2A). p38 inhibitor significantly reduced the loss in PG-treated CPAEC (Fig. 2A). JNK inhibitor alone triggered the loss in control CPAEC as well (Fig. 2A). In relation to MMP $\left(\Delta \Psi_{\mathrm{m}}\right)$ levels in CPAEC except negative Rhodamine 123 staining cells, PG did not affect MMP $\left(\Delta \Psi_{\mathrm{m}}\right)$ level in CPAEC (Fig. 2B). MEK and JNK inhibitors decreased the MMP $\left(\Delta \Psi_{\mathrm{m}}\right)$ level in PG-treated and -untreated CAPEC (Fig. 2B). In contrast, p38 inhibitor increased the level in PG-treated and -untreated CAPEC (Fig. 2B).

Effects of MAPK inhibitors on $\mathrm{ROS}$ and $\mathrm{O}_{2} \cdot$ levels in $P G$ treated CPAEC. We assessed the changes of the intracellular ROS levels in PG and/or each MAPK inhibitor-treated CPAEC. As shown in Fig. 3A, ROS (DCF) level such as $\mathrm{H}_{2} \mathrm{O}_{2}$ were significantly decreased in CPAEC treated with $\mathrm{PG}$ at $24 \mathrm{~h}$. None of MAPK inhibitors significantly alter the level in PG-treated CPAEC (Fig. 3A). All the MAPK inhibitors increased ROS levels in control CPAEC and p38 inhibitor treatment showed a strong effect (Fig. 3A). When we detected
$\mathbf{A}$

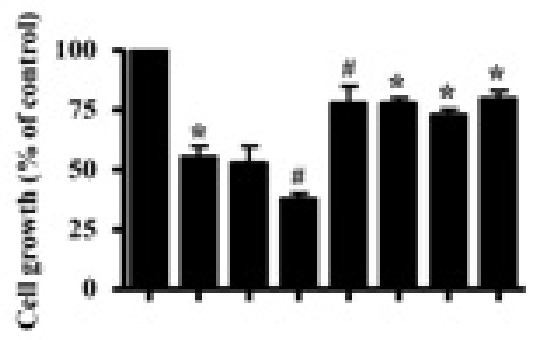

B

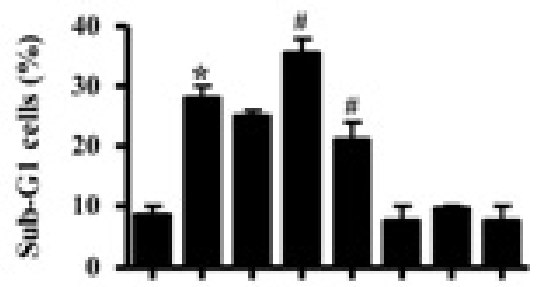

C

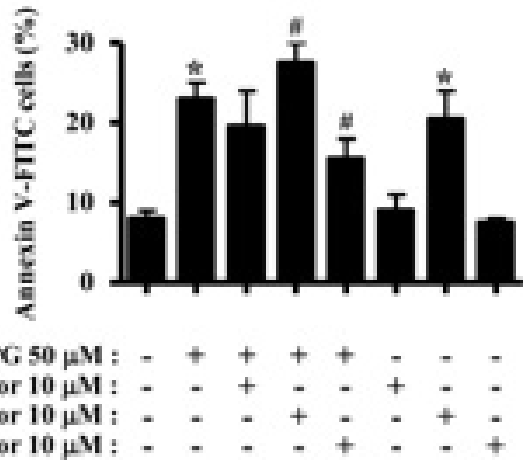

Figure 1. Effects of MAPK inhibitors on cell growth and death in PG-treated CPAEC. Exponentially-growing CPAEC were treated with PG for $24 \mathrm{~h}$ following 30 min pre-incubation of each MAPK inhibitor. (A) Graph shows CPAEC growth as assessed by the MTT assay. (B and C) Graphs show the percents of sub-G1 and (B) annexin V staining cells (C) as measured with a FACStar flow cytometer. ${ }^{*} \mathrm{P}<0.05$ compared with the control group. ${ }^{\#} \mathrm{P}<0.05$ compared with cells treated with PG only.

the intracellular $\mathrm{O}_{2}^{--}$levels in PG-treated CPAEC, red fluorescence derived from DHE reflecting intracellular $\mathrm{O}_{2}{ }^{-}$level was decreased at $24 \mathrm{~h}$ (Fig. 3B). None of MAPK inhibitors significantly changed $\mathrm{O}_{2}^{-}{ }^{-}$level in PG-treated CPAEC (Fig. 3B). MEK and JNK inhibitors increased $\mathrm{O}_{2}{ }^{-}$level in control CPAEC (Fig. 3B).

Effects of MAPK inhibitors on GSH levels in PG-treated $C P A E C$. When we analyzed the changes of GSH levels in CPAEC by using CMF fluorescence dye at $24 \mathrm{~h}, \mathrm{PG}$ increased the number of GSH depleted cells in CPAEC about $30 \%$ compared with PG-untreated control CPAEC (Fig. 4A). JNK inhibitor increased the number in PG-treated CPAEC whereas p38 inhibitor decreased the number (Fig. 4A). JNK inhibitor increased the number in control CPAEC (Fig. 4A). Furthermore, when CMF (GSH) levels in CPAEC except negative CMF staining cells were assessed, GSH level was increased in PG-treated CPAEC (Fig. 4B). JNK and p38 inhibitors slightly reduced the level in PG-treated CPAEC (Fig. 4B). All the MAPK inhibitor increased GSH levels in control CPAEC (Fig. 4B). 
A

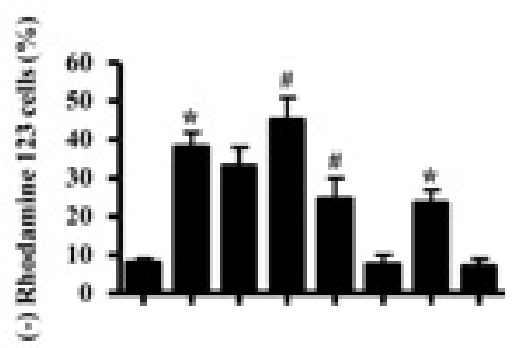

B

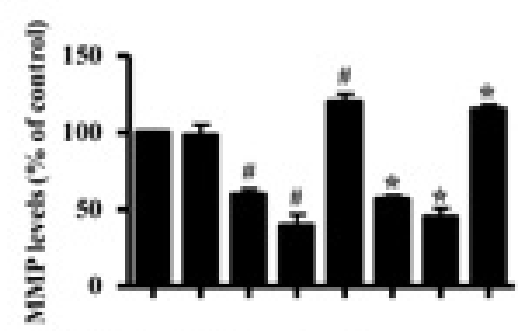

Figure 2. Effects of MAPK inhibitors on MMP $\left(\Delta \Psi_{\mathrm{m}}\right)$ in PG-treated CPAEC. Exponentially-growing CPAEC were treated with PG for $24 \mathrm{~h}$ following $30 \mathrm{~min}$ pre-incubation of each MAPK inhibitor. MMP $\left(\Delta \Psi_{\mathrm{m}}\right)$ in CPAEC was measured with a FACStar flow cytometer. (A and B) Graphs show the percents of Rhodamine 123 negative [MMP $\left(\Delta \Psi_{\mathrm{m}}\right)$ loss] cells (A) and MMP $\left(\Delta \Psi_{\mathrm{m}}\right)$ levels $(\%)$ compared with CPAEC control (B). ${ }^{*} \mathrm{P}<0.05$ compared with the control group. ${ }^{\#} \mathrm{P}<0.05$ compared with cells treated with PG only.

A

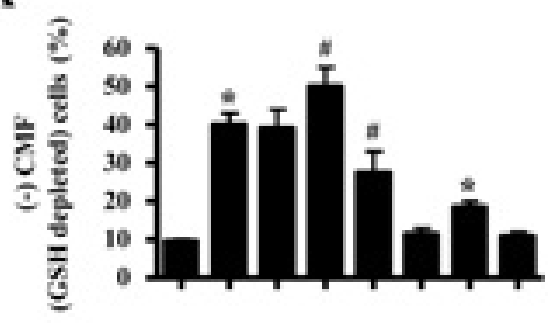

B

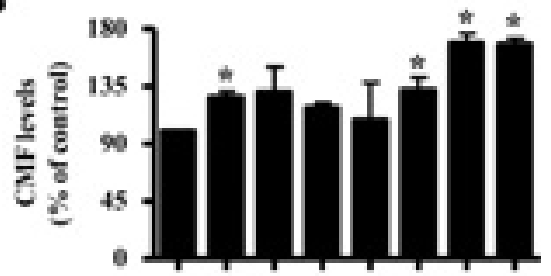

PG $50 \mu \mathrm{M}:-++++-\cdot$

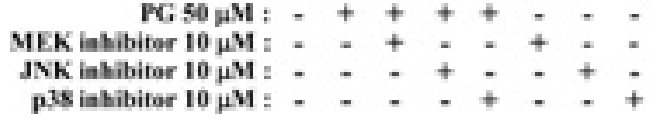

Figure 4. Effects of MAPK inhibitors on GSH levels in PG-treated CPAEC. Exponentially-growing CPAEC were treated with PG for $24 \mathrm{~h}$ following 30 min pre-incubation of each MAPK inhibitor. GSH levels in CPAEC were measured using a FACStar flow cytometer. (A and B) Graphs show the percent of (-) CMF (GSH depleted) cells (A) and mean CMF (GSH) levels compared with control CPAEC (B). ${ }^{*} \mathrm{P}<0.05$ compared with the control group. ${ }^{~} \mathrm{P}<0.05$ compared with cells treated with $\mathrm{PG}$ only.

A

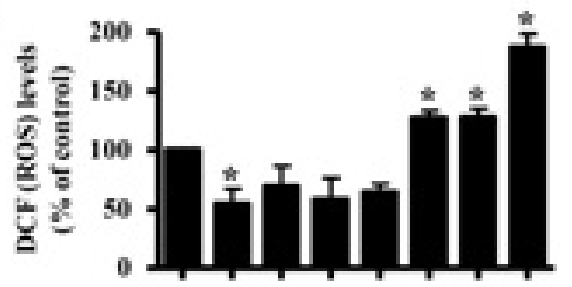

B

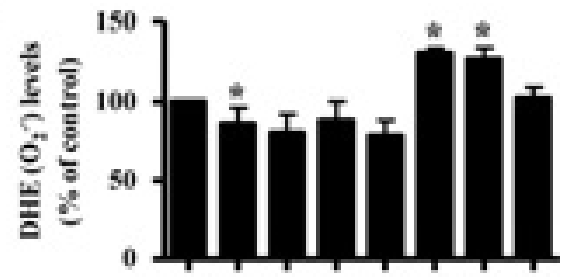

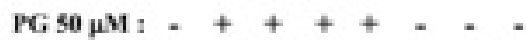

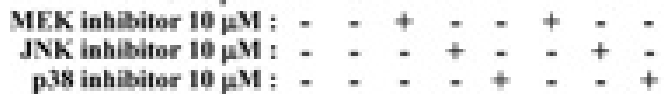

Figure 3. Effects of MAPK inhibitors on ROS levels in PG-treated CPAEC. Exponentially-growing CPAEC were treated with PG for $24 \mathrm{~h}$ following 30 min pre-incubation of each MAPK inhibitor. ROS levels in CPAEC were measured using a FACStar flow cytometer. (A and B) Graphs indicate DCF (ROS) and DHE $\left(\mathrm{O}_{2}{ }^{-}\right)$levels $(\%)$ compared with control CPAEC, respectively. ${ }^{*} \mathrm{P}<0.05$ compared with the control group.

\section{Discussion}

In the present study, we focused on evaluating the effects of MAPK inhibitors on PG-treated CPAEC in relation to cell death, ROS and GSH, since PG inhibited CPAEC growth and induced their death. ERK activation has a pro-survival function rather than pro-apoptotic effects (20). However, our result showed that MEK inhibitor in this study, which presumably inactivates ERK, did not increase sub-G1 and annexin V-FITC positive cells in PG-treated CPAEC. Thus, inactivation of ERK by MEK inhibitor did not seem to be an enhanced factor on PG-induced CPAEC death. It is known that JNK and p38 lead to apoptosis $(17,18)$. According to our data, JNK inhibitor increased CPAEC death by PG whereas p38 inhibitor decreased the death. These data imply that JNK and p38 signal transductions differently affect CPAEC death by PG. JNK signaling in PG-treated CPAEC seems to be involved in a pro-survival pathway whereas p38 signaling is likely to be related to a pro-apoptotic function. In particular, JNK inhibitor alone increased annexin V-FITC positive cells in control CPAEC, implying that the prevention of JNK signaling by its inhibitor was tightly related to CPAEC death. Moreover, MEK inhibitor did not affect the growth of PGtreated CPAEC. JNK inhibitor intensified the growth inhibition of PG-treated CPAEC whereas p38 inhibitor significantly prevented the growth inhibition. In addition, all the inhibitors inhibited control CPAEC growth. These data suggest that the signaling pathways of MAPKs differently affect CPAEC growth in the presence or absence of PG.

PG induces apoptosis in several types of cells such as mesangial cells (10), human lymphoma cells (1), human glioma cells (11) and Calu-6 lung cancer cells $(12,13)$. PG also 
triggered the loss of MMP $\left(\Delta \Psi_{\mathrm{m}}\right)$ in Calu-6 lung cancer cells $(12,13)$. Like-wise, PG induced apoptosis via the loss of MMP $\left(\Delta \Psi_{\mathrm{m}}\right)$ in CPAEC. MEK and p38 inhibitors decreased the loss of MMP $\left(\Delta \Psi_{\mathrm{m}}\right)$ in PG-treated CPAEC. These results suggest that MEK and p38 signalings are positively involved in the loss of MMP $\left(\Delta \Psi_{\mathrm{m}}\right)$ in PG-treated CPAEC. In contrast, JNK inhibitor increased the loss of MMP $\left(\Delta \Psi_{\mathrm{m}}\right)$ in PG-treated and -untreated CPAEC, implying that JNK signaling is involved in maintenance of MMP $\left(\Delta \Psi_{\mathrm{m}}\right)$ in these cells. In relation to MMP $\left(\Delta \Psi_{\mathrm{m}}\right)$ levels in CPAEC, PG did not affect $\operatorname{MMP}\left(\Delta \Psi_{\mathrm{m}}\right)$ level in viable CPAEC. MEK and JNK inhibitors decreased the MMP $\left(\Delta \Psi_{\mathrm{m}}\right)$ level in PG-treated and -untreated CAPEC. In contrast, p38 inhibitor increased the level in PGtreated and -untreated CAPEC. These results suggest that MAPK signalings differently affect MMP $\left(\Delta \Psi_{\mathrm{m}}\right)$ level in these cells.

PG can disturb the natural oxidation and reduction equilibrium in cells. For example, the increased patterns in $\mathrm{O}_{2}{ }^{-}$levels by PG were reported in pheochromocytoma PC12 cells (2), Calu-6 cells (27) and juxtaglomerular As4.1 cells (28). These data suggest that the apoptotic effects of PG are generally correlated with the changes of intracellular $\mathrm{O}_{2}{ }^{-}$ levels. However, our data showed that the intracellular ROS levels including $\mathrm{O}_{2}{ }^{-}$were decreased in PG-treated CPAEC at $24 \mathrm{~h}$. These data suggest that ROS level changes by PG are dependent of cell types. None of MAPK inhibitors significantly altered ROS level in PG-treated CPAEC. In addition, MEK and p38 inhibitors increased ROS levels in PG-untreated CPAEC without the induction of cell death. CPAEC death by PG and/or MEK and p38 inhibitors may not be correlated with ROS level changes. However, JNK inhibitor increased ROS levels in PG-untreated control CPAEC along with cell death and the loss of MMP $\left(\Delta \Psi_{\mathrm{m}}\right)$. Therefore, the exact role of ROS in CPAEC death needs to be defined further.

GSH, a main non-protein antioxidant in the cell, is able to clear away the $\mathrm{O}_{2}{ }^{--}$and provide electrons for enzymes such as glutathione peroxidase, which reduce $\mathrm{H}_{2} \mathrm{O}_{2}$ to $\mathrm{H}_{2} \mathrm{O}$ (29). It has been reported that the intracellular GSH content has a decisive effect on anticancer drug-induced apoptosis, indicating that apoptotic effects are inversely proportional to GSH content (30). Likewise, PG increased the number of GSH depleted cells in CPAEC. JNK inhibitor increased the number in PG-treated CPAEC whereas p38 inhibitor decreased the number. JNK inhibitor alone also increased GSH depleted cell number in CPAEC. These results seem to be correlated with annexin V-FITC results from CPAEC treated with PG and/or each MAPK inhibitor. Interestingly, GSH level in viable CPAEC was increased by treatment with PG. Probably, the relatively high GSH level resulted from the lower consumption of GSH due to the decreased ROS level by PG. In addition, all the MAPK inhibitors increased GSH levels in control CPAEC. The increased GSH levels might happen to reduce increasing ROS by each MAPK inhibitor.

In conclusion, $\mathrm{PG}$ induced apoptosis via the loss of MMP $\left(\Delta \Psi_{\mathrm{m}}\right)$ in CPAEC, which is accompanied by GSH depletion. JNK and p38 inhibitors increased and decreased apoptosis in PG-treated CPAEC, respectively, which correlated with GSH depletion results.

\section{Acknowledgements}

This study was supported by a grant of the Korea Healthcare Technology R\&D Project, Ministry for Health, Welfare \& Family Affairs and Republic of Korea (A084194) and the Korea Research Foundation Grant funded by the Government of the Republic of Korea (MOEHRD).

\section{References}

1. Saeki K, Hayakawa S, Isemura M and Miyase T: Importance of a pyrogallol-type structure in catechin compounds for apoptosisinducing activity. Phytochemistry 53: 391-394, 2000.

2. Yamada J, Yoshimura S, Yamakawa H, et al: Cell permeable ROS scavengers, Tiron and Tempol, rescue PC12 cell death caused by pyrogallol or hypoxia/reoxygenation. Neurosci Res 45: 1-8, 2003

3. Gonzalez C, Sanz-Alfayate G, Agapito MT, Gomez-Nino A, Rocher A and Obeso A: Significance of ROS in oxygen sensing in cell systems with sensitivity to physiological hypoxia. Respir Physiol Neurobiol 132: 17-41, 2002.

4. Baran CP, Zeigler MM, Tridandapani S and Marsh CB: The role of ROS and RNS in regulating life and death of blood monocytes. Curr Pharm Des 10: 855-866, 2004.

5. Bubici C, Papa S, Pham CG, Zazzeroni F and Franzoso G: The NF-kappaB-mediated control of ROS and JNK signaling. Histol Histopathol 21: 69-80, 2006.

6. Chen TJ, Jeng JY, Lin CW, Wu CY and Chen YC: Quercetin inhibition of ROS-dependent and -independent apoptosis in rat glioma C6 cells. Toxicology 223: 113-126, 2006.

7. Dasmahapatra G, Rahmani M, Dent P and Grant S: The tyrphostin adaphostin interacts synergistically with proteasome inhibitors to induce apoptosis in human leukemia cells through a reactive oxygen species (ROS)-dependent mechanism. Blood 107: 232-240, 2006.

8. Wallach-Dayan SB, Izbicki G, Cohen PY, Gerstl-Golan R, Fine $\mathrm{A}$ and Breuer R: Bleomycin initiates apoptosis of lung epithelial cells by ROS but not by Fas/FasL pathway. Am J Physiol Lung Cell Mol Physiol 290: L790-L796, 2006.

9. Simon HU, Haj-Yehia A and Levi-Schaffer F: Role of reactive oxygen species (ROS) in apoptosis induction. Apoptosis 5: 415-418, 2000

10. Moreno-Manzano V, Ishikawa Y, Lucio-Cazana J and Kitamura M: Selective involvement of superoxide anion, but not downstream compounds hydrogen peroxide and peroxynitrite, in tumor necrosis factor-alpha-induced apoptosis of rat mesangial cells. J Biol Chem 275: 12684-12691, 2000.

11. Sawada M, Nakashima $\mathrm{S}$, Kiyono T, et al: $\mathrm{p} 53$ regulates ceramide formation by neutral sphingomyelinase through reactive oxygen species in human glioma cells. Oncogene 20: 1368-1378, 2001.

12. Han YH, Kim SZ, Kim SH and Park WH: Pyrogallol inhibits the growth of lung cancer Calu-6 cells via caspase-dependent apoptosis. Chem Biol Interact 177: 107-114, 2009.

13. Han YH, Kim SZ, Kim SH and Park WH: Apoptosis in pyrogallol-treated Calu-6 cells is correlated with the changes of intracellular GSH levels rather than ROS levels. Lung Cancer 59: 301-314, 2008

14. Blenis J: Signal transduction via the MAP kinases: proceed at your own RSK. Proc Natl Acad Sci USA 90: 5889-5892, 1993.

15. Genestra M: Oxyl radicals, redox-sensitive signalling cascades and antioxidants. Cell Signal 19: 1807-1819, 2007

16. Kusuhara M, Takahashi E, Peterson TE, Abe J, Ishida M, Han J, Ulevitch $\mathrm{R}$ and Berk BC: p38 Kinase is a negative regulator of angiotensin II signal transduction in vascular smooth muscle cells: effects on $\mathrm{Na}^{+} / \mathrm{H}^{+}$exchange and ERK1/2. Circ Res 83: 824-831, 1998.

17. Hsin YH, Chen CF, Huang S, Shih TS, Lai PS and Chueh PJ: The apoptotic effect of nanosilver is mediated by a ROS- and JNK-dependent mechanism involving the mitochondrial pathway in NIH3T3 cells. Toxicol Lett 179: 130-139, 2008.

18. Mao X, Yu CR, Li WH and Li WX: Induction of apoptosis by shikonin through a ROS/JNK-mediated process in Bcr/Ablpositive chronic myelogenous leukemia (CML) cells. Cell Res 18: 879-888, 2008

19. Guyton KZ, Liu Y, Gorospe M, Xu Q and Holbrook NJ: Activation of mitogen-activated protein kinase by $\mathrm{H} 2 \mathrm{O} 2$. Role in cell survival following oxidant injury. J Biol Chem 271: 4138-4142, 1996. 
20. Henson ES and Gibson SB: Surviving cell death through epidermal growth factor (EGF) signal transduction pathways: implications for cancer therapy. Cell Signal 18: 2089-2097, 2006.

21. Bassenge E: Endothelial function in different organs. Prog Cardiovasc Dis 39: 209-228, 1996.

22. Park WH, Seol JG, Kim ES, Hyun JM, Jung CW, Lee CC, Kim BK and Lee YY: Arsenic trioxide-mediated growth inhibition in MC/CAR myeloma cells via cell cycle arrest in association with induction of cyclin-dependent kinase inhibitor, p21, and apoptosis. Cancer Res 60: 3065-3071, 2000

23. Han YH, Kim SZ, Kim SH and Park WH: Arsenic trioxide inhibits the growth of Calu-6 cells via inducing a G2 arrest of the cell cycle and apoptosis accompanied with the depletion of GSH. Cancer Lett (In press).

24. Han YH, Kim SZ, Kim SH and Park WH: Arsenic trioxide inhibits growth of As4.1 juxtaglomerular cells via cell cycle arrest and caspase-independent apoptosis. Am J Physiol Renal Physiol 293: F511-F520, 2007.

25. Han YH, Kim SH, Kim SZ and Park WH: Caspase inhibitor decreases apoptosis in pyrogallol-treated lung cancer Calu-6 cells via the prevention of GSH depletion. Int J Oncol 33: 1099-1105, 2008.
26. Yang J, Liu X, Bhalla K, Kim CN, Ibrado AM, Cai J, Peng TI, Jones DP and Wang X: Prevention of apoptosis by Bcl-2: release of cytochrome c from mitochondria blocked. Science 275: 1129-1132, 1997.

27. Han YH, Kim SH, Kim SZ and Park WH: Intracellular GSH levels rather than ROS levels are tightly related to AMAinduced HeLa cell death. Chem Biol Interact 171: 67-78, 2008.

28. Park WH, Han YW, Kim SH an dKim SZ: A superoxide anion generator, pyrogallol induces apoptosis in As4.1 cells through the depletion of intracellular GSH content. Mutat Res 619: 81-92, 2007.

29. Rhee SG, Yang KS, Kang SW, Woo HA and Chang TS: Controlled elimination of intracellular $\mathrm{H}(2) \mathrm{O}(2)$ : regulation of peroxiredoxin, catalase, and glutathione peroxidase via posttranslational modification. Antioxid Redox Signal 7: 619-626, 2005.

30. Estrela JM, Ortega A and Obrador E: Glutathione in cancer biology and therapy. Crit Rev Clin Lab Sci 43: 143-181, 2006. 